\title{
Morphological priming: Dissociation of phonological, semantic, and morphological factors
}

\author{
RAM FROST, AVITAL DEUTSCH, ORNA GILBOA, and MICHAL TANNENBAUM \\ Hebrew University, Jerusalem, Israel
}

and

WILLIAM MARSLEN-WILSON

\begin{abstract}
Previous experiments based on a masked-priming paradigm revealed robust morphological priming effects induced by two derivational morphemes in Hebrew: the root and the verbal pattern. However, considering the special characteristics of the masked-priming paradigm, the possible contributions of phonological and/or semantic factors to these morphological effects could not be firmly assessed. In the present study, the role of these factors in morphological priming was examined, using cross-modal presentation. Experiment 1 revealed that priming between morphologically related words in Hebrew is determined by higher level linguistic characteristics and cannot be reduced to phonological overlap. Experiment 2 confirmed that morphological priming occurs in Hebrew even when primes and targets are not semantically related but, nevertheless, increases with semantic similarity. The results support the claim that morphological priming cannot be accounted for by considering semantic and phonological factors alone, and they exemplify the potential of using both masked and cross-modal priming to examine morphological processing
\end{abstract}

To construct adequate models of lexical representation and processing, it is essential to determine the internal vocabulary in terms of which these processes are conducted. Is the primary unit of representation and analysis a unit corresponding to the surface word, or is the lexicon more appropriately modeled in terms of smaller, more abstract building blocks of lexical form and meaning, standardly called morphemes? Current opinion is moving more strongly toward some form of morphemic account, although the precise nature of this account remains controversial. Earlier studies (e.g., Taft, 1981; Taft \& Forster, 1975) argued for an across-the-board morphemic model, in which all potentially polymorphemic words were mandatorily decomposed into their morphemic components and initial access was via the base form. Recent studies have taken a more nuanced approach, suggesting that morphological analysis and decomposition occurs for some words, but not for others, although the studies employ widely divergent theoretical frameworks (e.g., Baayen, 1991; Burani \& Laudanna, 1992; Caramazza, Laudanna, \& Romani, 1988; Frauenfelder \& Schreuder, 1991; Frost, Forster, \& Deutsch, 1997; Marslen-Wilson, Tyler, Waksler, \& Older, 1994).

This study was supported in part by Binational Science Foundation Grant 94-00056, in part by National Institute of Child Health and Human Development Grant HD-01994, and in part by the Institute of Cognitive Studies, CNRS Lyon. We thank Meirav Margolin and Michal Master for their extensive help and assistance in running the experiments. Correspondence concerning this article should be addressed to R. Frost, Department of Psychology. Hebrew University, Jerusalem. 91905 Israel (e-mail: frost@mscc.huji.ac.il).
Further progress in illuminating these issues is impeded by the generally close correlation of morphological factors with semantic, orthographic, and phonological factors. In languages such as English, Italian, and Dutch, with which most current research has been conducted, a potential morphemic unit, such as the stem dark in English, is not only morphologically related to derived forms, such as darkness and darkly, but is also semantically and phonologically related. Furthermore, for English and Dutch, if not for Italian, it is very often the case that forms such as dark not only function as morphemes in complex forms, but are also free word-forms on their own account. These difficulties are compounded by the fact that a high proportion of the research into morphological factors in the mental lexicon has used repetition priming tasks, in which a target word is preceded by a prime word to which it is morphologically related. As various authors have pointed out (e.g., Rueckl, Mikolonski, Raveh, Miner, \& Mars, 1997; Seidenberg, 1987), it is particularly crucial under these conditions to separate out the potential contributions of phonological, semantic, and morphological factors to the priming effects that might be obtained. In the two experiments reported here, we take a different approach to the differentiation of these effects, exploiting the special properties of the Hebrew morphological system and examining the robustness of morphological effects across a variety of priming tasks.

\section{Hebrew Morphology}

We begin by outlining the special characteristics of Hebrew morphology. In Hebrew, most words can be decomposed into two abstract morphemes: the root and the 
word pattern. Roots, in most cases, consist of three consonants (there are few roots with two or with four consonants), whereas word patterns can be either a sequence of vowels or a sequence consisting of both vowels and consonants. These morphemes are not appended one to the other linearly, as in languages with concatenated morphology, such as English or Italian. Rather, the consonants of the root are intertwined with the phonemes (and therefore, the corresponding letters) of the word pattern. Roots and word patterns are abstract structures, because only their joint combination results in specific phonemic word-forms with specific meanings. These meanings cannot necessarily be predicted by analyzing the two morphemes independently one from the other. For example, the Hebrew noun MIKDAMA (meaning prepayment) consists of the combination of the root morpheme K.D.M (which conveys the meaning of advancing) with the word pattern MI--A-A (which conveys the grammatical form of feminine nouns; the dashed lines stand for the places where the root consonants are to be inserted into the word pattern). The same principle also applies to the verbal system. For example, the word HITKADEM, (meaning he advanced) is formed by the same root K.D.M interwoven with the word pattern HIT--A-E- (which denotes an active verbal form, commonly with a reflexive meaning).

These two basic morphemic units in Hebrew (the root and the word pattern) differ in their linguistic characteristics. In both the nominal and the verbal systems, the root carries the core meaning of the words. In contrast, the semantic specificity of word patterns differs within the derivational system of Hebrew nouns, as opposed to verbs. In the nominal system, word patterns (more than 100 ) convey primarily grammatical information about word class. Because of the large number of word patterns in the nominal system and their inconsistent semantic properties, the conceptual relations between different derivations of the same root in the nominal system may sometimes be opaque. In the verbal system, however, the role of word patterns is quite different. ${ }^{1}$ In contrast to the more than 100 different nominal patterns in which any root can be embedded to form a noun, there are only 7 different verbal patterns ( 3 active patterns, 3 passive patterns, and one reflexive form), ${ }^{2}$ and each conjugated form must be derived by using one of them. Thus, the same group of seven members repeats itself in the various conjugated verbs, making each form very salient. In addition, within the group of 7 verbal patterns, one can identify an internal system of mutual connections based on relatively consistent semantic relations (Ben-Asher, 1971). Thus, unlike the nominal forms, the actual meaning of a verbal form can often be predicted from analyzing its two morphological components (for a detailed description, see Deutsch, Frost, \& Forster, 1998). As we will explain in more detail below, this contrast in the semantic informativeness of the word patterns in the verbal and the nominal domains provides us with a special opportunity to tease apart the possible contribution of semantic and phonological components to morphological priming effects. The word patterns in both domains represent clear phonological patterns, but they differ in their semantic interpretability, relative to the word-form they help to construct.

\section{Priming Techniques in the Study of Morphology}

The most common method for examining the role of morphemic units in word recognition involves priming. Typically, the recognition of a target word is examined when it follows morphologically related and unrelated primes at different stimulus onset asynchronies (SOAs), or lags. Facilitation in processing the target word when it was preceded by a constituent morpheme or by an inflected or derived word is taken as evidence that the morphemic unit that is shared between the prime and the target has been activated, thereby governing lexical access to the target. Making this inference, however, is not completely straightforward, because priming between morphologically related words normally involves the partial repetition of form, as well as of semantic or grammatical information, and all of these features could determine the size of morphological effects. Disentangling the individual contribution of these components is crucial to the determination of how morphemic units are recognized and how they govern lexical access. In this context, we consider three major forms of priming: delayed repetition priming, immediate cross-modal repetition priming, and masked priming.

Historically, the most important of these has been delayed repetition priming, in which primes and targets share a specific morphemic unit and appear in a stimulus list with a variable number of items intervening between them (e.g., Bentin \& Feldman, 1990; Feldman, 1994; Fowler, Napps, \& Feldman, 1985; Stanners, Neiser, Hernon, \& Hall, 1979). Numerous studies have demonstrated that the recognition of morphologically related targets is facilitated even if many words separate the primes from the targets (see Stolz \& Feldman, 1995, for a review). For example, Drews and Zwitserlood (1995) have shown, in German and in Dutch, that morphological facilitation in the repetition priming paradigm is independent of simple form overlap. They reported similar results in contiguous priming, in which the primes and the targets followed each other, and in noncontiguous priming, in which 8-12 items separated the primes from the targets. This effect can be explained in morphological terms as reflecting the partial activation of the targets, given their lexical interconnections with the morphologically related primes (but see Rueckl et al., 1997, for alternative accounts). However, because of the significant delay between the presentations of the prime and the target, delayed repetition priming has consistently been criticized for being susceptible to episodic and strategic effects (e.g., Monsell, 1985). It is not always certain, with 
this task, whether priming effects reflect episodic procedural components, rather than the lexical and morphological links between primes and targets.

Here, we focus instead on two immediate repetition tasks, in which the prime immediately precedes the target, so that episodic effects can be safely ruled out. The first of these is masked priming, in which pairs of visual primes and targets are presented in such a way that the observer is not aware that a prime is present at all. A forward pattern mask is presented before the prime, and the temporal interval between the onset of the priming stimulus and that of the subsequent target stimulus is very brief (Forster \& Davis, 1984). One advantage of this procedure is that the very close temporal proximity of the prime and the target allows the investigator to pick up highly transient processing effects. Moreover, because the prime is masked, this effectively eliminates the possibility that the observed priming effects are the product of a conscious, retrospective appreciation of the relationship between the primes and the targets, thereby removing possible strategic effects.

A possible limitation of masked priming, however, as a means for probing the full range of properties of lexical representations, is that it is relatively insensitive to overlap at the level of semantic meaning. Although maskedpriming effects for associatively related pairs have been reported (e.g., Sereno, 1991), these effects are very weak or nonexistent, especially when the relationship is purely semantic (e.g., Perea, Gotor, Rosa, \& Algarabel, 1995). Thus, in morphological priming studies using this technique, the possible contribution of a semantic component to the morphological effect may not be measured (see also Frost et al., 1997). Another feature of masked priming is that it is predominantly sensitive to overlap at the level of orthographic form (see, e.g., Forster, Davis, Schoknecht, \& Carter, 1987; Forster \& Taft, 1994). Since words are presented in the visual modality, masked priming is likely to be informative primarily about the properties of the lexicon viewed from an orthographic perspective, with phonological factors having a secondary role. It is certainly possible, as recent PDP models of morphological processing have proposed (e.g., Rueckl et al., 1997), that morphological effects in visual word perception can be accounted for by taking into account possible correlation of orthographic units and semantic features. However, the primary mode for initial acquisition of language and its morphological properties is through the auditory modality. Speech remains, even in highly literate cultures, the dominant route for the input and output of morphological information. Thus, in building more general cognitive models of morphology in the mental lexicon, it is important to use tasks that are also potentially sensitive to the phonological aspects of the system. The full potential contribution of phonological factors to morphological effects, however, might be obscured by the masked-priming procedure, which is primarily sensitive to orthographic factors (Forster, 1987).
One task that seems to be more sensitive to phonological and semantic factors is the cross-modal immediate repetition task (Marslen-Wilson et al., 1994). In this paradigm, subjects are presented auditorily with a spoken word prime that is immediately followed by a visually presented target, to which they typically make a lexical decision response (note that the use of immediate repetition makes the task less susceptible to episodic effects than is standard delayed repetition). Latencies in a morphologically (and/or semantically) related condition are compared with a phonological control condition in order to assess the net priming effect. The fact that the prime is presented overtly, and in the auditory domain, means that any priming effects between morphologically related targets will reflect not only the morphological structure shared by the prime and the target, but also the possible contribution of semantic and phonological overlap, which may be relatively obscured in masked priming.

Obviously, in contrast to masked presentation, the overt exposure of the prime and the longer SOA between the primes and the targets render the investigation potentially more susceptible to biases deriving from the subjects' hypotheses about how the primes and the targets might be linked. But this simply adds to the complementarity of running the two types of task on the same materials. This offers the opportunity not only to tease apart the relative contributions of semantic and phonological factors to apparent morphological priming in the two tasks, but also to evaluate the possible contribution of strategic factors in the cross-modal experiments. For the present research, the underlying logic is straightforward: If the experimental task allows the phonological and semantic properties of the stimuli to be fully processed and morphological priming effects are found to be larger than the effects derived from either semantic or phonological overlap alone, this points to a contribution of morphological factors to the priming effect that cannot be reduced to the formal or semantic properties of the words. Following this logic, in Experiment 1 we will focus on the possible contribution of phonological effects by examining morphological priming induced by word-pattern morphemes, and in Experiment 2 we will focus on the contributions of semantic effects by examining morphological priming induced by root morphemes. In each case, we will run cross-modal versions of existing masked-priming studies of Hebrew morphology.

\section{EXPERIMENT 1}

In a series of recent studies, Frost, Deutsch, Forster, and their collaborators (see Deutsch et al., 1998; Frost et al., 1997) have employed the masked-priming paradigm to examine the role of roots and word patterns in Hebrew lexical organization and lexical access. In a first set of studies, looking at the nominal system, Frost et al. found that when primes and targets shared an identical word 
pattern, lexical decision or naming of targets was not facilitated. In contrast, root primes facilitated both lexical decision and the naming of target words that were derived from these roots. This suggested that Hebrew roots are lexical units and govern lexical access, whereas nominal word patterns are not. In contrast, however, in a further series of studies using masked priming, but now working within the verbal system, clear evidence was found for word-pattern priming as well as for root priming (Deutsch et al., 1988). This suggests that verbal word patterns have a much more distinct status as cognitive units than do noun patterns.

Given the apparently equal phonological saliency of noun and verb patterns in Hebrew words, Deutsch et al. (1998) attributed this result to differences between nominal and verbal patterns in their distributional properties (there are only 7 verb patterns, as opposed to over 100 noun patterns) and in their semantic transparency and predictability. However, it is a contrast that needs further empirical scrutiny - from the phonological perspective, in particular. The word pattern in Hebrew plays a central role in determining the phonological structure of the wordform as a whole. In contrast to concatenated morphologies such as English, in which morphologically complex words are formed primarily by combining existing fully specified phonological units, the Hebrew word-pattern morpheme is the primary determinant of the phonological structure of the entire complex form. In this respect, word-pattern priming might be expected to have a very strong phonological component, since the repeated pattern preserves the prosody, stress, vowel sequence, and some consonants of the prime word.

The puzzling failure, on this basis, of noun word patterns to prime successfully in the masked-priming task raises the possibility that masked priming, in which orthographic factors are predominant, may not be the most appropriate means for evaluating the phonological aspects of prime-target relations. Although the encoding of visual information into phonological structure is a wellestablished fact, an ongoing debate concerns the time course of phonological activation and the role it plays in the early stages of word processing, which are likely to be targeted by a visually masked presentation (see Frost, 1998 , for a review). Several studies have suggested that phonological priming effects may not be revealed under conditions of brief exposure (e.g., Shen \& Forster, 1999; and see Coltheart \& Woollams, 2000, for a discussion). In addition, since most nominal patterns are not repeatedly encountered in the language in the same way as are verbal patterns, the very brief exposure duration of the prime may not have been sufficient to allow their phonological structure to be fully recovered. This raises the possibility that the phonological properties of the nominal patterns could not have played their normal role in the processing and recognition of the primes, under visual masked presentation. In the cross-modal task, however, this would not be an issue, since the use of an unmasked spoken prime does ensure full processing and awareness of the phonological structure of the word pattern.
The use of cross-modal priming with the same sets of materials as those in the masked-priming experiment should allow us, therefore, to reevaluate the possible contribution of phonological factors to apparently morphological priming effects. In both nominal and verbal systems, word-pattern priming involves significant phonological overlap of primes and targets, but the repeated morphophonological material in the two systems differs in respect of other linguistic characteristics, such as consistency of semantic interpretation and relative distributional properties.

If the morphological priming effect reflects mainly phonological overlap between primes and targets, no difference should be observed in word-pattern priming in the nominal and verbal systems using cross-modal presentation. From a surface phonetic perspective, primes and targets sharing a word pattern have the same degree of overlap in both the nominal and the verbal system, sharing all the phonemes that do not belong to the three consonants of the root, as well as suprasegmental properties. Our aim in constructing Experiment 1 was, thus, to ensure that these properties have ample opportunities to be perceived and processed. If different priming effects are still found in the nominal and the verbal systems, while their phonological similarity is overtly exposed, it would strongly suggest that morphological priming, in both the masked and the cross-modal tasks, reflects a high level of linguistic analysis that cannot be reduced to simple surface properties, such as phonological overlap.

\section{Method}

Subjects. The subjects were 96 undergraduate students at the Hebrew University, all native speakers of Hebrew, who participated in the experiment for course credit or for payment. Forty-eight students participated in the nominal system condition experiment, and 48 in the verbal system condition.

Stimuli and Design. Within each system, the stimuli consisted of 48 printed target words and 48 target nonwords, which were paired with related or with unrelated auditory primes. Each target word served as its own control for assessing the effect of morphological relatedness. In the nominal system, the targets were singular words, four to six letters long, and contained two or three syllables with five to eight phonemes. In the verbal system, the primes and the targets were past tense, third-person singular forms, four or five letters long, containing two or three syllables with six to eight phonemes. A parallel set of 48 target nonwords in each word-class system were introduced as fillers. The nonwords were composed of the same word patterns as the words, but they included nonsense pseudoroots. This created pseudonominal forms and pseudo verbal forms.

Given the specific features of the cross-modal presentation that involves both auditory and visual presentation, both orthographic overlap and phonological overlap between the primes and the targets in the various experimental conditions are important elements. Since the subjects' decisions were given to the printed stimulus, control of phonological overlap was maintained at a maximum while keeping, at the same time, the same number of letters for primes and for targets. This allowed also a simple comparison with the masked-priming study, which had similar constraints. The primes in the related condition were words with the same phonological word pattern as the targets; in the control condition they had a different pattern that had the same number of letters, while preserving as much phonological similarity as possible. ${ }^{3}$ Obviously, manipulating the pattern entails differences in the syllabic structure of the 
related versus the control stimuli. Thus, phonological control was based mainly on keeping an equal number of shared consonants between the target and the related or control primes. However, since the experiment focused on the possible differences between nominal and verbal pattern priming, we were mainly concerned with maintaining any possible discrepancies related to syllabic structure as similar as possible for the nominal and the verbal stimuli. Thus, the mean number of syllables in the related versus the control condition was 2.56 and 2.62 for nominal forms and 2.04 and 2.29 for verbal forms. More important, the number of cases in which the number of syllables in the related and the control conditions was identical was virtually equal for the nominal and the verbal system (21 and
20 for the nominal and the verbal forms, respectively). With respect to the position of repeated phonological units, for both the nominal and the verbal forms, there were no cases in which the related prime had the same onset as the target and the control prime did not. The number of cases in which the target shared the same nucleus (the vowel of the rime) of the first syllable with the related prime, but not with the control prime, was, again, almost identical in the nominal (22) and the verbal (23) systems. Note that for both the nominal and the verbal stimuli, the primes and the targets in the related condition differed by the three consonants of the roots. The primes were spoken and recorded by a female native speaker, were digitized at a $20-\mathrm{kHz}$ sampling rate, and were edited with a waveform

\section{WORDS}

NOMINAL SYSTEM

\section{RELATED}

maqhela

(a choir)

מקהלה

Visual Target

mazmera

(a pruning shears)

מזר

מומרה

(a treasure)

מטון

mazmera

hugdar

(was defined)

הוגדר

הוגדר

\section{NONWORDS}

\begin{tabular}{|c|c|c|c|c|}
\hline \multirow[t]{3}{*}{ Auditory Prime } & margema & mapteax & huz̧ak & hiSmit \\
\hline & (a mortar) & (a key) & (was alarmed) & (omitted) \\
\hline & מרגמה & מפתח & הוזעק & השמיט \\
\hline \multirow[t]{2}{*}{ Visual Target } & malkena & malkena & huS $\zeta a z$ & huS $̧ a z$ \\
\hline & מלקנה & מלקנה & הושעז & הושעז \\
\hline
\end{tabular}

NOMINAL PATTERN: MA- -E-A

VERBAL PATTERN: HU- -A-

Figure 1. Examples of the nominal and verbal forms employed in Experiment 1. 
editor. Examples of the stimuli employed in the experiment are presented in Figure 1, and the full set of stimuli is available from the corresponding author.

In order to avoid repetition effects, within each word system the stimuli were divided into two lists. Each list contained 24 primetarget pairs in the related condition, 24 prime-target pairs in the unrelated condition, and 48 word-nonword pairs. Pairs that were related in one list were unrelated in the other, and vice versa. Twentyfour different subjects were tested on each list in the two word systems.

Procedure and Apparatus. The subjects were seated in front of a Macintosh II computer screen (9-in. diagonal, screen size). They were instructed to listen to the primes and make lexical decisions to the targets. The auditory stimuli were transmitted binaurally to the subject's headphones by the computer, and the following visual presentation triggered the computer's clock for reaction time (RT) measurements. Each trial began with a row of "+" signs appearing on the screen for 1,000 msec. A 100 -msec auditory warning beep followed the plus signs, and the auditory presentation of the prime occurred immediately thereafter. The visual presentation of the target was timed to appear $200 \mathrm{msec}$ after the offset of the auditory presentation, and it remained on the screen until the subject pressed the response button. The dominant hand was always used for the yes response. The intertrial interval was $500 \mathrm{msec}$. Each session began with 16 practice trials, which were followed by the 96 test trials, all presented in one block.

\section{Results}

Correct lexical decision latencies were averaged across subjects and across items in the related and unrelated conditions, for the nominal and the verbal systems. Within each subject/condition combination, RTs that were outside a range of $2 S D$ s from the respective mean were excluded, and the mean was recalculated. Outliers accounted for less than $5 \%$ of all the responses. One stimulus from the nominal and one from the verbal system were excluded from the analysis because of excessive error rates. The results are presented in Table 1.

Overall, RTs to related targets were faster than RTs to unrelated targets, and RTs to nominal targets were faster than RTs to verbal targets. However, the main finding of the present study was the differential effect of morphological priming in the nominal and verbal systems: A large effect of word-pattern priming was obtained in the verbal system $(+24 \mathrm{msec})$, whereas in the nominal sys-

Table 1

Reaction Times (RTs, in Milliseconds) and Percentages of Errors for Lexical Decisions to Target Words and Nonwords in the Related and Unrelated Conditions Within the Nominal and Verbal Systems

\begin{tabular}{|c|c|c|c|c|}
\hline \multirow[b]{2}{*}{ Condition } & \multicolumn{2}{|c|}{ Nominal System } & \multicolumn{2}{|c|}{ Verbal System } \\
\hline & RT & Error & RT & Error \\
\hline \multicolumn{5}{|c|}{ Words } \\
\hline Related & 548 & 7.0 & $5 \mathrm{I} 2$ & 8.0 \\
\hline Control & 557 & 7.0 & 536 & 8.0 \\
\hline Priming effect & +9 & & +24 & \\
\hline \multicolumn{5}{|c|}{ Nonwords } \\
\hline Related & 632 & 8.1 & 609 & 14.1 \\
\hline Control & $63 !$ & 6.0 & 605 & 12.2 \\
\hline Priming effect & -1 & & -4 & \\
\hline
\end{tabular}

tem this effect was reduced to +9 msec only. The results were subjected to a two-way analysis of variance, in which the prime condition (related, unrelated) was one factor and the word system (nominal, verbal) was another. All the reported tests were significant at the .05 level, unless otherwise noted.

Both of the main effects were reliable, but our hypothesis was concerned with the interaction of morphological relatedness and word system. This interaction was significant in both the subjects and the item analy$\operatorname{ses}\left[F_{1}(1,94)=4.5, M S_{\mathrm{e}}=602 ; F_{2}(1,92)=4.4, M S_{\mathrm{e}}=\right.$ 835]. Planned comparisons revealed that the effect of morphological relatedness was highly significant in the verbal system $\left[F 1(1,47)=18.4, M S_{\mathrm{e}}=722 ; F_{2}(1,46)=\right.$ $\left.24.1, M S_{\mathrm{e}}=627\right]$. In contrast, in the nominal system, morphological relatedness was marginally significant by subjects $\left[F_{1}(1,47)=3.7, M S_{\mathrm{e}}=482, p<.06\right]$ and not significant by items $\left[F_{2}(1,46)=1.3, M S_{\mathrm{e}}=1044, p<\right.$ .3]. The error analysis did not yield any effects for any factor $\left(F_{1}\right.$ and $\left.F_{2}<1\right)$. Similarly, morphological relatedness had no effect on nonwords $\left(F_{1}\right.$ and $\left.F_{2}<1\right)$.

\section{Discussion}

This study, taken in conjunction with the earlier masked-priming study, allows us to evaluate the relative contribution of phonological factors and higher order linguistic factors to the strength of priming between pairs of morphologically related stimuli. Two apparently identical morphemic units--Hebrew word patternswere examined in the nominal and in the verbal systems. In both systems, word patterns are the principal determinants of the phonological structure of the word. They vary, however, in their higher order properties, as well as in their distributional properties. In the verbal system, the highly repeated, limited number of word patterns conveys semantic and syntactic information in a relatively systematic manner, but in the nominal system this is done much less consistently. The results suggest that it is these properties that determine the structure of underlying morphological representations and, therefore, whether morphological priming is obtained. When the primes and the targets shared a verbal pattern, significant cross-modal priming occurred, because both the primes and the targets accessed the same underlying morpheme. In contrast, when primes and target shared a nominal word pattern, no significant priming was found, since nominal patterns do not have independent representations as lexical morphemes.

This result allows us to address two questions raised in the introduction. First, it shows that priming between morphologically related words in Hebrew cannot be reduced to phonological priming. When the phonological form of the prime is made fully explicit, by presenting it overtly and auditorily, there is no change in the direction or the size of the contrast between nominal and verbal patterns. In particular, there is no sign of an increase in the amount of priming for the nominal patterns, relative to the masked-priming case, which is what one would ex- 
pect if masked priming in some way underestimates the role of phonological factors in the relationship between nominal primes and targets, given their special distributional properties. More generally, this result is also consistent with research in English showing that priming effects caused by morphological relations between primes and targets cannot be explained by simple phonological factors (Marslen-Wilson et al., 1994).

Second, as these comparisons suggest, the results confirm that masked priming does tap into abstract levels of lexical representation. The commonality between masked and overt cross-modal tasks indicates that the pattern of priming obtained in the original Frost et al. (1997) and Deutsch et al. (1998) studies was not due to form-level effects but reflects, instead, the underlying decomposition of primes and targets into their morphological components and the different lexical status of verbal-pattern and nominal-pattern morphemes.

\section{EXPERIMENT 2}

The second experiment was designed along lines parallel to the first, but with the focus now shifting to the contribution of semantic factors to apparent morphological priming. This is an important issue in justifying morphological interpretations of priming studies, but one that perhaps cannot be straightforwardly resolved in languages like English, in which morphological decomposability seems to be closely related to semantic transparency. Although the interaction of morphological decomposability and semantic transparency has been evaluated in Dutch and English (e.g., Baayen, 1991; Schreuder \& Baayen, 1995; Stolz \& Feldman, 1995), Hebrew offers a relatively rich environment for investigating these issues, both because of its nonconcatenative morphology and because of the relatively frequent occurrence of words that are morphologically related but not transparently semantically related. For example, both HADRAKA (guidance) and DRIKUT (alertness) are derivations of the root D.R.K., which conveys the meaning of stepping. Although it is possible to trace the historical evolution of these derivations from the root, their semantic overlap in modern Hebrew seems opaque. Native speakers are nonetheless able to identify the common root in DRIKUT and HADRAKA and will judge them to be morphologically related, but not semantically related (see, e.g., Ben-Dror, Bentin, \& Frost, 1995). Furthermore, the derivational structure based on the combination of the two abstract morphemes enables us to examine the effect of semantic relatedness between morphologically related words by manipulating semantic features via morphological units that do not function as independent words (e.g., a shared root). This unique feature provides the opportunity to monitor semantic properties without the lexical mediation of a word prime.

Research so far suggests that there is a contrast between Hebrew and English in the extent to which morphological and semantic factors are interdependent. In research with English, using cross-modal immediate repetition, Marslen-Wilson et al. (1994) found that morphologically related words did not prime each other unless they were also semantically related. Thus, whereas morphologically related $(\mathrm{M}+)$ and semantically related $(\mathrm{S}+)$ pairs, like darkness/dark, did prime each other effectively, pairs like department/depart, which are morphologically but not semantically related, did not prime at all. Comparable results are reported by Feldman and Soltano (1999), who found no priming between opaque pairs (such as $\mathrm{Ca}$ sualty/casualness) when these were presented in a visualvisual priming task with a prime duration of $250 \mathrm{msec}$. These results seem to contrast with findings with Hebrew. In an earlier study using delayed repetition priming, Bentin and Feldman (1990) showed that repetition effects for words sharing the same root but with different meanings were significant even at long lags, whereas effects of simple semantic association were found only at short lags. Words that shared the same root and were also semantically related showed the most robust repetition priming effects at short lags. In a subsequent maskedpriming study, however, Frost et al. (1997) found that priming effects for morphologically related words were almost identical for semantically related and unrelated targets. Finally, Raveh and Feldman (1998) have recently reported that morphological facilitation in Hebrew varied with degree of semantic relatedness.

Experiment 2 reexamined the relative contribution of semantic and morphological factors to morphological priming effects, using the immediate repetition crossmodal task. This achieves three ends. First, it allows a direct comparison with the research in English, using parallel stimulus materials in the same experimental paradigm. Second, it allows us to evaluate more directly the respective roles of semantic and morphological factors than is possible using the masked priming task alone. As we noted earlier, masked priming is generally insensitive to semantic relations between a prime and a target, so the nature and size of a potential semantic component of morphological priming effects in Hebrew cannot be estimated by the use of this task alone. As we know from the research in English, cross-modal immediate repetition is sensitive to both morphological and semantic links between primes and targets. Effects of semantic relatedness in this paradigm have been already demonstrated in the classical work of Swinney (1979). More recently, MarslenWilson and his collaborators (1994) have extended these findings, showing robust effects of morphological relatedness as well. Third, as in Experiment 1, the comparison between the two tasks has useful methodological consequences, allowing us to determine more directly the respective roles of the masked and the cross-modal tasks as tools for probing mental representations in the mental lexicon.

\section{Method}

Subjects. The subjects were 60 undergraduate students at the Hebrew University, ail native speakers of Hebrew, who participated in the experiment for course credit or for payment.

Stimuli and Design. The stimuli consisted of 48 target nominal root derivations, which were four to seven letters long and contained two or three syllables with five to eight phonemes. Their mean num- 
ber of letters was 5.0 and their mean number of phonemes was 6.5 . The target words were paired with 192 primes to create four experimental conditions, with 48 pairs in each condition. In the morphologically and semantically related $(\mathrm{M}+\mathrm{S}+)$ condition, the prime was a derivation of the same root as the target, and its meaning was semantically related to that of the target. In the morphologically related and semantically unrelated $(\mathrm{M}+\mathrm{S}-)$ condition, the prime was a derivation of the same root as the target, but its meaning had no apparent semantic relation with that of the target. In the phonological control condition, the prime shared with the target the same nominal pattern (i.e., the same number of letters and phonemes as in the related condition) but consisted of a derivation from a different root. Finally, in another control condition, the prime and the target did not share any letters or phonemes. The purpose of the two control conditions was to reexamine whether phonological similarity by itself would create facilitation or inhibition that might also contribute to priming effects between morphologically related pairs. Examples of the stimuli are given in Figure 2, and the full set of stimuli employed in the experiment is available from the corresponding author.

On average, primes and targets overlapped by 3.4 phonemes in the $\mathrm{M}+\mathrm{S}+$ and $\mathrm{M}+\mathrm{S}-$ conditions and by 3.3 phonemes in the phonological control condition. This kept phonological (and orthographic) similarity constant across experimental conditions. The semantic similarity of primes and targets was assessed by averaging ratings of 50 judges on a 7 -point scale, from unrelated (1) to highly related $(7)$. The average rating of semantic relatedness for pairs in the $\mathrm{M}+\mathrm{S}+$ condition was 5.27 (with a minimal relatedness score of 4.5 ), whereas the average judged relatedness in the $\mathrm{M}+\mathrm{S}-$ condition was only 1.85 (with a maximal relatedness score of 2.5). Assuming that the subjects could have been biased in their semantic judgment by the apparent morphological connection, this relatedness score seems to be exceptionally close to the score in the phonological control condition, which was 1.15 (with a maximal relatedness score of 2.4). This reflects the special characteristics of Hebrew morphology, which allows for minimal semantic overlap between morphologically related words.

In addition to the words, 48 prime-target nonword pairs were introduced as fillers. The nonwords were composed of the same nominal word patterns as the words but contained nonsense pseudoroots. Similar to the word targets, the nonwords were also divided into four experimental conditions. This, however, reflected nothing but a formal division for the purpose of achieving a symmetry in the experimental design. Obviously, there were no semantic relations between the nonword fillers.

The stimuli were divided into four lists, each containing 12 words and 12 nonwords in each of the four experimental conditions (96 prime-target pairs in each list). The subjects were assigned to one of the four lists randomly. The stimuli were rotated within the four conditions in each list by a Latin-square design, so that each subject would be tested in all four experimental conditions, the subjects would see each target word only once, and each target word would

$\mathrm{M}+\mathrm{S}+\mathrm{S}-\quad \begin{gathered}\text { phonological unrelated } \\ \text { control }\end{gathered}$

WORDS

Auditory Prime

madrix

(a guide)

דרทา

hadraxa

(guidance)

הדרכה

Visual Target

hadraxa
(guidance)
הדרכה

\begin{abstract}
drixut
\end{abstract}
(alertness)

דריכות

hadraxa

הדרכה

חาרว

mhudar

(fancy)

מדור

hadraxa

Slemut

(perfection)

שלמות

hadraxa

הדרכה

ROOT: DRK

*Because of phonetic rules, the phoneme $/ \mathrm{k} /$ is pronounced in all above examples as [ $\mathrm{x}]$.

\section{Example of Nonwords:}
Auditory Prime:
brexa
בריכה (pool)

Visual Target:

hamraxa

המרכה

Figure 2. Examples of the stimuli employed in Experiment 2. 
Table 2

Reaction Times (RTs; in Milliseconds) and Percentages of Errors for Lexical Decisions to Target Words in the Morphologically and Semantically Related $(\mathbf{M}+\mathbf{S}+)$, the Morphologically Related and Semantically Unrelated $(\mathrm{M}+\mathrm{S}-)$, and the Two Control Conditions in Experiment 2

\begin{tabular}{lccccc}
\hline Measure & Control & $\begin{array}{c}\text { Phonological } \\
\text { Control }\end{array}$ & $\mathrm{M}+\mathrm{S}+$ & $\mathrm{M}+\mathrm{S}-$ & $\begin{array}{c}\text { Nonword } \\
\text { Fillers }\end{array}$ \\
\hline RTs & 525 & 531 & 489 & 505 & 598 \\
Errors & 7.8 & 6.9 & 3.8 & 7.3 & 4.1
\end{tabular}

$\mathrm{M}+\mathrm{S}+$ priming effect: $42 \mathrm{msec}$

$M+S$ - priming effect: $26 \mathrm{msec}$

Note-Effects are calculated relative to the phonological control condition.

be paired with its four respective primes across lists. Fifteen subjects were tested in each list. The procedure and apparatus were identical to those employed in the previous experiment.

\section{Results}

The procedures for data analysis were analogous to those of Experiment 1. Outliers accounted for less than $5 \%$ of all the responses. The results are presented in Table 2.

The effect of prime condition was significant by both subjects and items $\left[F_{1}(3,132)=18.9, M S_{\mathrm{e}}=946\right.$; $\left.F_{2}(3,141)=19.2, M S_{\mathrm{e}}=1,036\right]$. The nature of the effect of prime condition was that responses in the $\mathrm{M}+\mathrm{S}+$ condition were faster than responses in the $\mathrm{M}+\mathrm{S}-$ condition and responses in both morphological priming conditions were faster than those in both control conditions.

The crucial comparison concerns priming in the $\mathrm{M}+\mathrm{S}-$ condition. Planned comparisons revealed that facilitation in this condition was significant both by subjects and by items $\left[F_{1}(1,59)=17.6, F_{2}(1,47)=16.9\right]$. The amount of facilitation in the two morphologically related conditions did, however, differ significantly, with $16 \mathrm{msec}$ greater facilitation in the $\mathrm{M}+\mathrm{S}+$ condition $\left[F_{1}(1,59)=\right.$ $\left.6.2, F_{2}(1,47)=6.5\right]$. Finally, the two control conditions did not differ significantly $\left(F_{1}\right.$ and $\left.F_{2}<1\right)$.

Error rates were similar in the $\mathrm{M}+\mathrm{S}-$ condition and the two control conditions, with a smaller error rate in the $\mathrm{M}+\mathrm{S}+$ condition. The error analysis revealed a significant effect of prime condition in the subject analysis $\left[F_{1}(3,132)=4.5, M S_{\mathrm{e}}=2.2\right]$, but not in the item analysis $\left[F_{2}(3,141)=1.5\right]$.

\section{Discussion}

The results of Experiment 2 confirm that morphological priming occurs in Hebrew even when primes and targets are derived from the same root but are not semantically related. Although the average semantic relatedness in the $\mathrm{M}+\mathrm{S}-$ condition was similar to the relatedness in the phonological control condition, significant priming was found. To ensure that the slight difference in semantic relatedness judgments between the $\mathrm{M}+\mathrm{S}-$ condition and the control condition (1.85 vs. 1.15) was not the source of the priming effect, we calculated the correlation between the size of the effect and the difference in rating of semantic similarity. This correlation was not only small and nonsignificant, but also negative $(r=$ $\left.-.11, R^{2}=.01\right)$. This outcome, which concurs with the findings of Frost et al. (1997) with masked priming, clearly suggests that the source of the priming effect reflects morphological processes that are not constrained by semantic factors. These results contrast with parallel findings with English (Marslen-Wilson et al., 1994).

However, in contrast to the masked priming experiments, the cross-modal presentation revealed that the priming effect increases with semantic similarity. Lexical decisions to targets that were related both morphologically and semantically to their primes were significantly faster than lexical decisions to targets that had no semantic overlap with their primes. Given the relatively prolonged time course characteristic of the cross-modal presentation, the locus of the additional contribution of semantic relatedness to morphological priming cannot be unequivocally determined. On the one hand, it may reflect processes mediating lexical access. On this view, semantic factors affect the strength of morphological connection with the lexicon. On the other hand, the additional semantic contribution could simply reflect a postlexical facilitation. We will consider below the implications of these findings both for theories of lexical organization and for the experimental methods used to probe lexical structure and function.

\section{GENERAL DISCUSSION}

The comparison across languages and between tasks in these two studies constitutes strong evidence for the existence of a morphological dimension to lexical organization that cannot be reduced simply to phonological or semantic relations between primes and targets. In Experiment 1 , the differences between nominal and verbal word patterns, as primary morphological components of the Hebrew word, were preserved across masked-priming and cross-modal tasks. As was noted earlier, the word pattern is the primary constituent of the phonological structure of a word, specifying its syllabic and suprasegmental properties, as well as its vowels and some of its consonants. The failure of nominal patterns to prime in the cross-modal task, in which the overt auditory presentation of the prime provides ample opportunity for these phonological properties to be extracted, indicates that the priming effects here, as well as in the masked priming task, reflect higher order properties of lexical organization. Furthermore, Deutsch et al. (1998) suggest that these differences in priming relations for verbal and nominal patterns are also likely to reflect underlying differences in the distributional properties of word-pattern morphemes in the two domains. These differences determine whether a morphological unit will have a lexical status that affects lexical access. But whether or not this 
specific account is correct, the important point is that morphological processing has to be conducted in a decompositional framework, in which word patterns are separated from the roots and in which priming relations between these components vary according to their status and function as independent morphemes, as was demonstrated in Experiment 1.

In Experiment 2, using a task that is sensitive to both morphological and semantic relations between primes and targets, we see a strong priming effect preserved between pairs whose relationship is semantically opaque but that share the same underlying root morpheme. Although semantic links can contribute to the priming effects between morphologically complex words, it is clear that the priming effect for the $\mathrm{M}+\mathrm{S}-$ pairs cannot be reduced to a semantic relationship. Nor is a form-based (orthographic and/or phonological) account viable, given the properties of the controls and of the cross-modal task in general. Again, the priming effects require an analysis in which surface words are decomposed into abstract constituent morphemes - abstract because they never appear themselves as surface forms - and in which priming reflects the repeated activation of the same underlying morpheme.

The second set of conclusions concerns the respective roles of such tasks as masked priming and cross-modal repetition priming in probing lexical organization. It is clear, first, that both tasks are sensitive to morphological effects - that is, to the ways in which abstract lexical elements (morphemes) combine and recombine in the perceptual analysis and interpretation of spoken words. The results of Experiment 2, together with the earlier results using the masked-priming task (Deutsch et al., 1998), demonstrate that the processes of morphemic analysis have a functional integrity that does not depend on semantic support. At the same time, the results also indicate a useful difference between the two tasks. Cross-modal priming, in addition to its sensitivity to purely morphological effects, is also sensitive to semantic similarity between a prime and a target. This offers the potential of using the two tasks in tandem to tease out, in particular, problematic cases, whether the priming relationship is semantic, morphological, or both.

Finally, returning to the cross-linguistic dimension, the results raise the issue of why we find such marked differences between Hebrew and English in terms of the interdependence between morphological and semantic relatedness. In English, we see evidence for morphological decomposition of complex forms only when the relationship between the full form and its constituent morphemes is semantically transparent and compositional (i.e., when the primary meaning of the form, for current speakers of the language, is derivable by combining the meanings of stem and affix, as in forms like darkness and avoidable). For Hebrew this is evidently not the case, as Experiment 2 confirms, using a task and materials directly comparable with those used in English.

To properly evaluate the reasons for this major crosslinguistic difference, we will need comparable evidence from additional languages. Given just the Hebrew and English data, we can attribute the difference either specifically to the special properties of nonconcatenative morphology (as in Hebrew), as opposed to concatenative morphology (as in English), or more generally to differences in the role that morphology plays in word structure, where English may contrast with a range of languages, including some with concatenative morphological systems. The likely contrast here is not just in the extent and the richness of a language's morphological system, but also in the degree to which morphological combination and analysis is an obligatory part of the representation and processing of words in the language-both at the level of underlying lexical entries and as phonetically realized surface forms.

English may represent a language in which the majority of surface forms are monomorphemic words that have no internal morphological structure and whose representation and processing is based on the properties of stored semantic and phonological whole units and does not involve any obligatory morphological analysis. Most morphologically complex words, furthermore, involve the concatenation of free stems and derivational morphemes, where each unit is an independent phonological entity. Whether these distinct entities are viewed as being combinatorially linked in underlying representation then becomes a matter of choice for the language learner, depending on whether the combinatorial account of some complex form gives the correct semantic outcome.

In contrast, for languages like Hebrew, morphological combination is an obligatory component of almost every surface word. Words are generated as combinations of abstract underlying morphemes, and these need to be recovered in the process of perceptual analysis and interpretation. The listener or the speaker is engaged in processes of morphological analysis, irrespective of the semantic compositionality of the morphological components involved, simply in order to generate or to decode the surface form in question. This role of morphology in determining the basic form of the word operates structurally, and it is this basic structural role that is then picked up in experiments involving primes that are morphologically but not semantically related. The same underlying root or verbal pattern plays a structural role in processing both the prime and the target, producing the priming observed here and in the masked-priming experiments.

An obligatory role for morphology in almost every surface word is by no means unique to nonconcatenative languages like Hebrew. For a wide variety of languages, every surface form is essentially morphologically complex. In further research, we will need to examine the potential dissociability of semantic and morphological factors for languages like these.

\section{REFERENCES}

BAAYEN, H. (1991). Quantitative aspects of morphological productivity. In G. Booij \& J. Van Marle (Eds.), Yearbook of morphologv (pp. 109149). Dordrecht: Kluwer. 
BEN-Asher, M. (1971). Do verbal patterns concern the grammar or the dictionary? [In Hebrew]. The University, 16, 31.34.

Ben-Dror, I., Bentin, S., \& Frost, R. (1995). Semantic, phonological, and morphological skills in children with reading disabilities and normally achieving readers: Evidence from perception and production of spoken Hebrew words. Reading Research Quarterly, 30. 876893.

BEntin, S., \& Fel.dman, L. B. (1990). The contribution of morphological and semantic relatedness to the repetition effect at long and shor lags: Evidence from Hebrew. Quarterly Journal of Experimental Psychology, 42A, 693-711.

Burani, C., \& Laudanna, A. (1992). Units of representation of derived words in the lexicon. In R. Frost \& L. Katz (Eds.), Orthography, phonology, morphologv, and meaning (pp. 27-44). Amsterdam: North-Holland.

Caramazza, A.. Laudanna, A., \& Romani, C. (1988). Lexical access and inflectional morphology. Cognition, 28, 207-332.

Coltheart, M. \& Woollams, A. (2000). Does KliP prime clip? Masked priming by phonological primes. Manuscript submitted for publication.

Deutsch, A, Frost, R., \& Forster, K. I. (1998). Verbs and nouns are organized and accessed differently in the mental lexicon; Evidence from Hebrew. Journal of Experimental Psychology: Learning, Memory, \& Cognition, 24, 1238-1255.

Drews, E.. \& Zwitserlood, P. (1995). Morphological and orthographic similarity in visual word recognition. Journal of Experimental Psychology: Human Perception \& Performance, 21, 1098-1116.

FELDMAN. L. B. (1994). Beyond orthography and phonology: Differences between inflections and derivations. Journal of Memory \& Language, 33, 442-470.

Feldman L. B., \& Soltano, E. G. (1999). Morphological priming: The role of prime duration, semantic transparency, and affix position. Brain \& Language, 68, 33-39.

ForSTER, K. I. (1987). Form-priming with masked primes: The bestmatch hypothesis. In M. Coltheart (Ed), Attention and Performance XII: The psychologv of reading (pp. 127-146). Hillsdale, NJ: Erlbaum.

Forster, K. I., \& DAVIS, C. (1984). Repetition priming and frequency attenuation in lexical access. Journal of Experimental Psychology: Learning, Memory, \& Cognition, 10, 680-698.

Forster, K. I., Davis, C., Schoknecht, C., \& Carter, R. (1987) Masked priming with graphemically related forms: Repetition or partial activation? Quarterly Journal of Experimental Psychology, 39A, $211-251$.

FORSTER, K. I., \& TAFT, M. (1994). Bodies, antibodies, and neighborhooddensity effects in masked form priming. Journal of Experimental Psychology: Learning, Memory, \& Cognition, 20, 844-863.

FowLER. C. A., NAPPS, S. E., \& FELdMAN, L. (1985). Relations among regular and irregular morphologically related words in the lexicon as revealed by repetition priming. Memory \& Cognition, 13, 241 . 255.

Frauenfelder, U. H., \& Schreuder, R. (1991). Constraining psycholinguistic models of morphological processing and representation: The role of productivity. In G. Booij \& J. Van Marle (Eds.), Yearbook of morphology (pp. 165-183). Dordrecht: Kluwer.

FROST, R. (1998). Towards a strong phonological theory of visual word recognition: True issues and false trails. Psychological Bulletin, 123, $71-99$.

Frost, R., Forster. K. I., \& Deutsch, A. (1997). What can we learn from the morphology of Hebrew: A masked priming investigation of morphological representation. Journal of Experimental Psychology: Learning, Memory, \& Cognition, 23, 829-856.

Marslen-Wilson, W. D., Tyler. L. K.. Waksler, R., \& Older, L.
(1994). Morphology and meaning in the English mental lexicon. Psychological Review, 101, 3-33.

MonselL, S. ( 1985). Repetition and the lexicon. In A. W. Ellis (Ed.), Progress in the psychology of language (Vol. 2, pp. 147-196). Hove, U.K.: Erlbaum.

Perea, M., Gotor, A., Rosa, E., \& Algarabel, S. (1995, November). Time course of semantic activation for different prime-target pairs in the lexical decision task. Poster presented at the 36th Annual Meeting of the Psychonomic Society, Los Angeles.

Raveh, M., \& Feldman, L. B. (1998, September). The contribution of morphological relation and affix position to morphological processing. Paper presented at the Congress of the European Society for Cognitive Psychology, Jerusalem.

Rueckl, J. G., Mikolonski, M., Raveh, M., Miner, C., \& Mars, F. (1997). Morphological priming, fragment completion, and connectionist networks. Joumal of Memory \& Language, 36, 382-405.

SCHREUDER, R., \& BAAYEN, R. H. (1995). Modeling morphological processing. In L. B. Feldman (Ed.), Morphological aspects of language processing (pp. 131-154). Hillsdale, NJ: Erlbaum.

SEIDENBERG, M. S. (1987). Sublexical structures in visual word recognition: Access units or orthographic redundancy? In M. Coltheart (Ed.), Attention and performance XII: The psychology of reading (pp. 244-263). Hillsdale, NJ: Erlbaum.

SERENO. J. A. (1991). Graphemic, associative, and syntactic priming effects at brief stimulus onset asynchrony in lexical decision and naming. Journal of Experimental Psychology: Learning, Memory, \& Cognition, 17, 459-477

SHEN, D., \& Forster, K. I. (1999). Masked phonological priming effects in reading Chinese words depends on the task. Language \& Cognitive Processes, 14, 429-459.

Stanners, R. F., Neiser, J. J., hernon, W. P., \& Hall, R. (1979). Memory representation for morphologically related words. Journal of Verbal Learning \& Verbal Behavior, 18, 399-412.

Stolz, J. A., \& Feldman, L. B. (1995). The role of orthographic and semantic transparency of the base morpheme in morphological processing. In L. Feldman (Ed.), Morphological aspects of language processing (pp. 109-129). Hillsdale, NJ: Erlbaum.

SWINNEY, D. (1979). Lexical access during sentence comprehension. Journal of Verbal Learning \& Verbal Behavior, 15, 681-689.

TAFT, M. (1981). Prefixed stripping revisited. Journal of Verbal Learning \& Verbal Behavior, 20, 289-297.

TAFT, M., \& ForSTER, K. I. (1975). Lexical storage and retrieval of prefixed words. Journal of Verbal Learning \& Verbal Behavior, 14, 638-647.

\section{NOTES}

1. The main grammatical distinction in Hebrew is between nominal and verbal patterns. This is because there are different inflectional rules for both types of patterns. Within the nominal system, the same grammatical rules apply for both noun and adjectives, and the distinctions between them are made on a semantic basis. Thus, the same pattern could form an adjective or a noun, depending on the root embedded in it, and the same word could serve as a noun or an adjective in different syntactic contexts.

2. But note that although each of the verbal patterns can be characterized semantically as conveying active, passive, or reflexive action in a way that distinguishes it from the other patterns, there are often counterexamples in the system.

3. The number of shared phonemes between the prime and the target is often smaller by one phoneme in the phonological control condition than in the related condition, because of the constraint of keeping the same number of letters while manipulating the pattern. 
APPENDIX

The Hebrew Alphabet

\begin{tabular}{|c|c|c|}
\hline $\begin{array}{c}\text { Hebrew } \\
\text { Print }\end{array}$ & $\begin{array}{l}\text { Orthographic } \\
\text { Transcription }\end{array}$ & $\begin{array}{l}\text { Phonetic } \\
\text { Transcription }\end{array}$ \\
\hline$N$ & r & r \\
\hline J & $\mathrm{b}$ & $b, v$ \\
\hline$\lambda$ & $\mathrm{g}$ & $\mathrm{g}$ \\
\hline 7 & $\mathrm{~d}$ & $\mathrm{~d}$ \\
\hline ה & $\mathrm{h}$ & $\mathrm{h}$ \\
\hline I & w & $o, u, v$ \\
\hline t & $\mathrm{z}$ & $z$ \\
\hline$\Pi$ & $\mathrm{x}$ & $\mathrm{x}$ \\
\hline 0 & $\theta$ & $\mathrm{t}$ \\
\hline , & $y$ & $\mathrm{I}, \mathrm{y}$ \\
\hline 2 & $\mathrm{k}$ & $k, x$ \\
\hline 7 & K & $\mathrm{x}$ \\
\hline ל & 1 & 1 \\
\hline$D$ & $\mathrm{~m}$ & $\mathrm{~m}$ \\
\hline 0 & M & $\mathrm{m}$ \\
\hline $\mathrm{J}$ & $\mathrm{n}$ & $\mathrm{n}$ \\
\hline 1 & $\mathrm{~N}$ & $\mathrm{n}$ \\
\hline o & $\mathrm{s}$ & $\mathrm{s}$ \\
\hline$y$ & $s$ & $\varsigma$ \\
\hline 0 & $\mathrm{p}$ & $p, f$ \\
\hline$\eta$ & $\mathrm{P}$ & f \\
\hline$y$ & šs & šs \\
\hline$\psi$ & $\breve{S}$ & S \\
\hline$p$ & $q$ & $\mathrm{k}$ \\
\hline ? & $\mathrm{r}$ & $\mathrm{r}$ \\
\hline ש & $\mathrm{S}$ & $\mathrm{S}$ \\
\hline$\pi$ & t & $\mathrm{t}$ \\
\hline
\end{tabular}

(Manuscript received August 25, 1998;

revision accepted for publication January 9, 2000.) 